\title{
EDITORIAL
}

ISSN 1598-9100(Print) • ISSN 2288-1956(Online)

INTESTINAL

RESEARCH

http://dx.doi.org/10.5217/ir.2015.13.2.103

Intest Res 2015;13(2):103-104

\section{Are Small Rectal Neuroendocrine Tumors Safe?}

\author{
Jae Ho Choi, Jae Myung Cha \\ Department of Internal Medicine, Kyung Hee University Hospital at Gang Dong, Kyung Hee University School of Medicine, Seoul, Korea
}

\section{Article: Natural Course of an Untreated Metastatic Perirectal Lymph Node After the Endoscopic Resection of a Rectal Neuroendocrine Tumor (Intest Res 2015;13:175-179)}

Neuroendocrine tumors (NETs) are slow-growing tumors with different biological and clinical characteristics. The incidence of NETs varies depending on the organ; however, the rectum is the most prevalent tumor site in the gastrointestinal system, accounting for $60-89 \%$ of all gastrointestinal NETs. ${ }^{1}$ These tumors are often found incidentally during colonoscopy without any symptoms. They are usually detected on endoscopy as small, protruding subepithelial lesions located between $4-20 \mathrm{~cm}$ above the dentate line on the anterior or lateral rectal wall. According to the European Neuroendocrine Tumor Society (ENETS) 2012 Consensus Guidelines, ${ }^{2}$ well-differentiated rectal NETs $<10 \mathrm{~mm}$ without muscle invasion or lymph node involvement could be treated by performing local resection. For local resection, various treatment modalities have evolved, including endoscopic polypectomy, endoscopic mucosal resection (EMR), endoscopic submucosal dissection, transanal excision, and transanal endoscopic microsurgery. ${ }^{3}$

To evaluate the risk of metastasis, pathological examination of lymph nodes should be implemented. However, small rectal NETs are known to have little risk of metastasis, making local resection desirable. Radical surgery is reserved for selected cases with risk factors associated with lymph node metastasis. In rectal NETs $<10 \mathrm{~mm}$, the risk of lymph node metastasis is low. However, the risk of lymph node metastasis increases remarkably in rectal NETs with larger

Received March 11, 2015. Accepted March 11, 2015.

Correspondence to Jae Myung Cha, Department of Internal Medicine, Kyung Hee University Hospital at Gang Dong, Kyung Hee University School of Medicine, 892 Dongnam-ro, Gangdong-gu, Seoul 134-727, Korea. Tel: +82-2-440-6113, Fax: +82-2-440-6295, E-mail: drcha@khu.ac.kr

Financial support: None. Conflict of interest: None. than $10 \mathrm{~mm} .{ }^{4,5}$ Although CT scans do not reflect lymph node metastasis as accurately as a pathologic examination, a case may be regarded as negative for lymph node metastasis if no signs of metastasis appear using $\mathrm{CT}^{6}{ }^{6}$ Therefore, the authors of the current case $^{7}$ re-examined a 7 -mm perirectal lymph node identified on a CT scan after EMR for a 8-mm rectal NET. The pathological type of tumor also significantly affects the risk of metastasis. ${ }^{8}$ According to the WHO 2000 pathological diagnostic criteria for gastrointestinal NETs based on tissue structures, tumors are graded into three levels on the basis of tumor cell proliferation: tumors with a grade of G1 have a mitotic count $<2$ per 10 high-power fields (HPF) and/ or Ki-67 $\leq 2 \%$; G2, mitotic count $2-20$ per $10 \mathrm{HPF}$ and/or Ki$673-20 \%$; and G3, mitotic count $>20$ per $10 \mathrm{HPF}$ and/or Ki$67>20 \%$. In the current case, ${ }^{7}$ it may be reasonable to omit surgical resection for the perirectal lymph nodes after EMR, as histological analysis of the tumor revealed no lymphovascular invasion, no mitosis per $50 \mathrm{HPF}$, and a Ki-67 labeling index of $0.8 \%$.

In the current case, the authors followed the patient using annual endoscopy and abdominopelvic CT for 7 years after resection. Fortunately, the perirectal lymph node metastasis was completely removed via laparoscopic surgical resection and lymph node dissection, vigorous surveillance in this case. A population-based study in Japan also reported a prevalence of $3.7 \%$ for lymph node metastasis in rectal NETs $<5 \mathrm{~mm}$ and $10 \%$ for tumors $<10 \mathrm{~mm}$. In a retrospective study by the Colonoscopy Study Group of the Korean Society of Coloproctology, ${ }^{6} 7$ of 359 (1.95\%) tumors less than $10 \mathrm{~mm}$ had lymph node metastasis. In two other Japanese studies, ${ }^{9,10}$ Kasuga et al. ${ }^{9}$ reported a prevalence of $4.9 \%$ for lymph node metastasis in G1 tumors $\leq 10 \mathrm{~mm}$, and Konishi et al. ${ }^{10}$ reported a higher metastatic rate (as high as $7 \%$ ) in rectal NET

๑ Copyright 2015. Korean Association for the Study of Intestinal Diseases. All rights reserved.

This is an Open Access article distributed under the terms of the Creative Commons Attribution Non-Commercial License (http://creativecommons.org/licenses/by-nc/3.0)

which permits unrestricted non-commercial use, distribution, and reproduction in any medium, provided the original work is properly cited. 
$\leq 10 \mathrm{~mm}$, but did not indicate the tumor grades. As the risk of lymph node metastasis in rectal NETs $\leq 10 \mathrm{~mm}$ vary between studies, ${ }^{4,6,9,10}$ local resection may be complicated, even in small rectal NETs. Therefore, careful surveillance is essential, especially when lymph node metastasis cannot be predicted accurately, as in the current case. Currently, there is no data recommending regular follow-up after local resection of rectal NETs $<10 \mathrm{~mm}$. ENETS guidelines ${ }^{2}$ recommend annual follow-up for G3 tumors $<10 \mathrm{~mm}$ and G1-G3 tumors 10-20 $\mathrm{mm}$. In addition, ENETS guidelines recommend follow-up for G1-G2 tumors $>20 \mathrm{~mm}$ within the first year, and every 4-6 months in the first year and at least annually thereafter for G3 tumors.

In the current case, the authors followed the patient using annual endoscopy and abdominopelvic CT. Although ENETS guidelines ${ }^{3}$ do not recommend routine follow-up with CT or MRI for rectal NETs $<10 \mathrm{~mm}$, follow-up modalities may include endoscopy, EUS or MRI. Considering the possibility of lymph node metastasis in the first presentation of the current case, additional investigation with rectal MRI or EUS that can more accurately assess perirectal lymph nodes than conventional CT may be helpful in assessing the nature of perirectal lymph node enlargement. ${ }^{11}$ Furthermore, EUSguided fine needle aspiration or laparoscopic lymph node sampling may be considered if MRI or EUS suggests the possibility of lymph node metastasis. As the natural course of rectal NETs is not fully understood and the risk of lymph node metastasis has varied in previous studies, the metastatic potential of rectal NETs, even in tumors $<10 \mathrm{~mm}$, should not be ignored.

The current case report is very informative for clinicians, because the natural course of untreated perirectal lymph node metastasis of G1 rectal NETs $<10 \mathrm{~mm}$ has never been described previously. Generally, the risk of lymph node metastasis for rectal NETs $<10 \mathrm{~mm}$ is low; however, NETs are classified as a malignant disease in the recently revised American Joint Committee on Cancer (AJCC) cancer staging guidelines. Therefore, clinicians should remember that the clinical behavior of rectal NETs might sometimes resemble that of malignant tumors, even when tumors are small.

\section{REFERENCES}

1. Ito T, Sasano H, Tanaka M, et al. Epidemiological study of gastroenteropancreatic neuroendocrine tumors in Japan. J Gastroenterol 2010;45:234-243.

2. Caplin M, Sundin A, Nillson O, et al. ENETS Consensus Guidelines for the management of patients with digestive neuroendocrine neoplasms: colorectal neuroendocrine neoplasms. Neuroendocrinology 2012;95:88-97.

3. Kim GU, Ye BD, Byeon JS, et al. Endoscopic resection for rectal carcinoid tumor: efficacy and clinical results of follow-up. Intest Res 2011;9:217-224.

4. Soga J. Early-stage carcinoids of the gastrointestinal tract: an analysis of 1914 reported cases. Cancer 2005;103:1587-1595.

5. Al Natour RH, Saund MS, Sanchez VM, et al. Tumor size and depth predict rate of lymph node metastasis in colon carcinoids and can be used to select patients for endoscopic resection. J Gastrointest Surg 2012;16:595-602.

6. Colonoscopy Study Group of Korean Society of Coloproctology. Clinical characteristics of colorectal carcinoid tumors. J Korean Soc Coloproctol 2011;27:17-20.

7. Kim SH, Yang DH, Lee JS, et al. Natural course of an untreated metastatic perirectal lymph node after the endoscopic resection of a rectal neuroendocrine tumor. Intest Res 2015;13:175179.

8. Rindi G, Arnold R, Bosman FT, et al. Nomenclature and classification of neuroendocrine neoplasms of the digestive system. In: Bosman FT, Carneiro F, Hruban RH, Theise ND, eds. WHO classification of tumours of the digestive system. 4th ed. Lyon: IARC, 2010:13-14.

9. Kasuga A, Chino A, Uragami N, et al. Treatment strategy for rectal carcinoids: a clinicopathological analysis of 229 cases at a single cancer institution. J Gastroenterol Hepatol 2012;27:18011807.

10. Konishi T, Watanabe T, Kishimoto J, Kotake K, Muto T, Nagawa $\mathrm{H}$; Japanese Society for Cancer of the Colon and Rectum. Prognosis and risk factors of metastasis in colorectal carcinoids: results of a nationwide registry over 15 years. Gut 2007;56:863868.

11. Taylor FG, Quirke P, Heald RJ, et al. Preoperative high-resolution magnetic resonance imaging can identify good prognosis stage I, II, and III rectal cancer best managed by surgery alone: a prospective, multicenter, European study. Ann Surg 2011;253:711719. 